\section{2,000 eggs a day.)”}

Did an over-enthusiastic spellcheck cause a Reuters story on the honeybee genome, published in Nature last week, to go somewhat beyond the scientists' findings?

\section{“Everything from making a fighter more fuel-efficient to looking at the materials that munitions are made of.")}

Spokeswoman Deborah Allen explains how arms-maker British Aerospace is investing in more environmentally friendly weapons.

\section{(CMoney was spent on the Russian mafia as we tried to clone mammoths. You can't say that so we expensed it as money for cows.)"}

Woo Suk Hwang finally takes the stand in his defence (see page 12).

\section{ZOO NEWS}

\section{Hot hedgehogs}

As the British get ready for 5 November celebrations of bonfires and fireworks, the Hedgehog Preservation Society is pleading for people to check bonfires before lighting them. "Piles of bonfire material look like fivestar hotels to a hedgehog," it warns.

\section{OVERHYPED}

It is dogma in the public-health community that the stigma of being HIV positive fuels the epidemic. The theory goes that people are afraid to use condoms, say, or seek testing, for fear that others might suspect their HIV status. But in a provocative essay in PLoS Medicine, Daniel Reidpath and Kit Yee Chan say there's no evidence for this. Establishing the link requires longitudinal data on levels of stigma and rates of infection, or at least a correlation between them in different areas.

Sources: $B B C$, Reuters

\title{
Ethiopian plan for Lucy tour splits museums
}

Lucy, the famed Ethiopian fossil, may soon take to the sky to sparkle on her first US tour. But where the 3.2-million-year-old hominid will travel after an initial appearance in Houston is unclear, with many anthropologists fearing that the risk to the fragile skeleton is too great.

On 24 October, Ethiopian government officials announced an agreement with the Houston Museum of Natural Science to exhibit Lucy's skeleton and nearly 200 other artefacts, beginning in September 2007. Few have seen the Lucy remains, found in 1974 and named after the song Lucy in the Sky with Diamonds by The Beatles. The skeleton, which is $40 \%$ complete, is kept in a vault in the basement of the Ethiopian National Museum in Addis Ababa.

If palaeoanthropologists agree on anything, it is that original fossils should not travel, to keep them safe and available for research. A policy statement issued by the International Association for the Study of Human Paleontology says that valuable remains should be moved

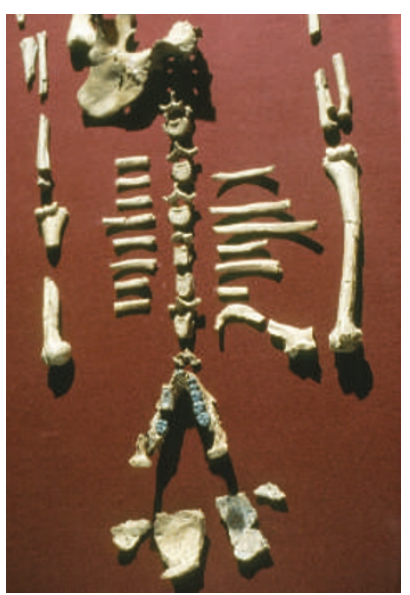

Stay at home: researchers say that Lucy is too fragile to travel. of a near-complete Homo erectus youth.

The Kenyans then announced that the exhibit would lead to the return of some Kenyan antiquities held in the Field Museum - notably the Tsavo lions, stuffed man-eaters famous a century ago for killings outside Mombasa. But Neil Shubin, provost of the Field Museum, says he was stunned. "There was never a formal proposal made for an exhibit," he says, adding that there is no plan to send the lions back.

Details of the Lucy tour, including where it will appear and how much money Ethiopia will get, are also unclear. Major US museums, including the American Museum of Natural History in New York and the Smithsonian Institution, say they are not interested, out of concern for the remains. Bartsch admits that no other museums have signed up yet, but says he anticipates intense interest for a ten-city tour.

Jara Haile Mariam, manager of the Ethiopian culture ministry's Authority for Research and Conservation of Cultural Heritage, says that Ethiopia hopes to get US\$5-6 million from the tour, with only for "compelling scientific reasons". Casts are typically displayed instead.

But Joel Bartsch, president of the Houston museum, argues that museums such as his have the expertise to handle delicate specimens. He sees the exhibit as an opportunity "to raise the profile of a country that is home to the cradle of mankind".

Sating public hunger for historical reality can bring sorely needed funds to the home countries of valuable artefacts. The Tutankhamun tour, currently being visited by throngs across the United States, has brought Egypt millions of dollars to help it preserve its antiquities. But whereas Egypt has kept the most valuable human remains at home, Ethiopia and Kenya seem willing to tour their prize exhibits.

In another attempt at a high-profile fossil tour, officials from the National Museums of Kenya flew to the Field Museum in Chicago in September to propose an exhibit centred on Nariokotome Boy, a 1.6-million-year-old fossil museums paying about $\$ 300,000$ each for four-month exhibitions, plus a percentage of the takings. The Ann and Robert H. Lurie Foundation is also reported to have pledged $\$ 1$ million, but Bartsch and the foundation declined to comment on the financial details.

Despite the difficulties over agreeing terms, those who advocate sending African fossils abroad say it will allow them to be studied at high-tech US institutions, and will encourage tourism and trade in their countries of origin by inspiring Western museum-goers.

But many palaeoanthropologists are concerned by the trend. "This makes no sense," says Meave Leakey, whose husband Richard's team found the Nariokotome Boy in 1984. She argues that there are already adequate resources for analysis in Africa. As for increasing tourism: "This is the reverse of what will logically happen. If the fossils can be viewed in the United States, why travel to Ethiopia or Kenya?" Rex Dalton 